\title{
Ganadería e integración del espacio regional: la organización y la gestión de las pasturas en las fronteras de la Corona de Aragón, siglos XII-XIV
}

\author{
VICENT Royo PÉREZ
}

PALABRAS CLAVE: ganadería, frontera, Corona de Aragón, Edad Media.

CÓDIGOS JEL: N53, Q20, Q24, R14.

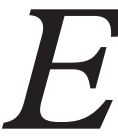

n este artículo se pretende analizar la gestión de los espacios de pastura en la región fronteriza entre Cataluña, Aragón y Valencia durante los siglos XII-XIV. Desde la conquista cristiana de los siglos XII y XIII, la sociedad rural que se articula en los límites de estas tres entidades politicas se integra en un modelo económico determinado por la ganadería. Primero, la monarquía y los señores favorecen la creación de un gran espacio ganadero $y$, a medida que se aleja la frontera con los musulmanes, la ganadería se convierte en la actividad económica principal de los habitantes de los concejos. Surgen, entonces, intereses contrapuestos entre los diferentes grupos sociales y emerge una conflictividad generalizada en la región que deriva del establecimiento de distintos usos y derechos sobre los pastos. De hecho, se arbitran diferentes sistemas de gestión comunal y privada de las pasturas y, progresivamente, las villas y las comunidades rurales adquieren una gran autonomía en su administración por delegación de los señores respectivos. Así pues, nuestra intención es analizar la evolución de las diversas formas de gestión de los espacios de pastura y conocer la problemática derivada de su combinación en el seno de una sociedad rural. 


\title{
Livestock farming and regional integration: organization and management of the pastures in the borders of the Crown of Aragón, $12^{\text {th }}-14^{\text {th }}$ centuries
}

\author{
KEYWORDS: livestock, border, Crown of Aragón, Middle Ages.
}

\section{JEL CODES: N53, Q20, Q24, R14.}

$n$ this article, we analyse the management of pasturelands in the border areas of
Catalonia, Aragón and Valencia during the twelfth to fourteenth centuries. As
Muslim territories receded with the Christian conquest of the twelfth and thirteenth centuries, the monarchy and the feudal lords favoured the creation of a large livestockproducing area. Livestock thus became the main economic activity for people living in towns and rural communities along the borders of these three political areas. The establishment of diverse rights and uses related to pasturelands gave rise to confrontations among social groups and conflict throughout the region. As systems for communal and private management of pastures were negotiated, feudal lords increasingly delegated management to towns and rural communities, which gradually obtained greater autonomy. Our aim is to analyse the evolution, amalgamation and issues associated with pasture management systems in a rural society.

Recepción: 2018-07-06 • Revisión: 2019-03-11 • Aceptación: 2019-03-30

Vicent Royo Pérez [orcid.org/0000-0003-2486-2118] es doctor en Historia por la Universitat faume I de Castelló y, actualmente, ejerce como profesor asociado en la Universitat Autònoma de Barcelona. Dirección para correspondencia: Departament de Ciències de l'Antiguitat i de l'Edat Mitjana, Universitat Autònoma de Barcelona, Facultat de Filosofia $i$ Lletres, 08193, Bellaterra (España). C.e. vicent.royo@uab.cat; vicent.royo@gmail.com 


\section{INTRODUCCIÓN}

Hasta el último cuarto del siglo xx, la ganadería se presentaba como una actividad complementaria a una agricultura que ejercía un papel dominante. El ritmo de la vida en el campo se explicaba a partir de los ciclos agrícolas y la caracterización de la empresa campesina se detallaba a partir de la explotación agraria, es decir, del conjunto de tierras que componían los diversificados patrimonios agrícolas de los campesinos. Asimismo, la organización del territorio era definida tomando como referencia las zonas de cultivo y se subrayaba la difícil integración de la ganadería en un paisaje articulado alrededor de dichos espacios. En este discurso, se reconocía la relevancia de la ganadería, pero se tendía más a señalar su conflictiva relación con la agricultura hegemónica que a estudiar su peso en las explotaciones campesinas, su influencia en la organización del territorio y la gestión de unos espacios de aprovechamiento ganadero que constituían un aspecto central en el funcionamiento de las comunidades rurales ${ }^{1}$.

Esta tendencia de análisis ha sido complementada por otra vertiente de estudio que, desde hace unas décadas, ha analizado la ganadería y ha demostrado que dicha actividad es esencial en la comprensión de la sociedad rural, tanto en los aspectos económicos como paisajísticos. Así pues, se ha analizado la especialización de ciertas regiones en la ganadería ovina y las particularidades que imprime esta orientación productiva en las economías señoriales y campesinas (Jover, 1994: 81-99; Pascua, 2007: 209-238; Riera, 2004: 751-764; Royo, 2010a: 25-56). Esto ha permitido conocer la integración de estas regiones especializadas en la producción de lana en los flujos económicos regionales e internacionales, un aspecto que ha roto con la tradicional visión de aislamiento del campo. Con relación al paisaje, se han descrito las rutas de trashumancia (Gerbet, 2003; Laffont, 2006; Pascua, 2012) y se ha demostrado que las cañadas, los abrevaderos y los pasturajes tienen un papel esencial en la organización del espacio (Brumont, 2008; Fernández Mier, López Gómez \& González Álvarez, 2013: 167-219; Martín Gutiérrez, 2015; Royo, 2011: 123-142). Evidentemente, la interacción de la ganadería y la agricultura siempre resulta conflictiva, y esta difícil convivencia exige la articulación de complejos sistemas de gestión colectiva de los diferentes espacios (Ferrer, 1990: 485-539; Bourin, 2007: 179-192; Riera, 2007: 221-250). Existe, pues, un proceso de estructuración progresiva del territorio que necesariamente debe considerar a la ganadería para poder entender su evolución ${ }^{2}$.

1. Este planteamiento se encuentra en los clásicos manuales de historia agraria (SLICHER van BATH, 1978) y también en otros más recientes (GIRALT, 2004).

2. Una síntesis de las líneas de investigación sobre la ganadería, en FERNÁNDEZ MiER, López Gómez y González Álvarez (2013: 168-172). Para la Corona de Aragón, aunque tiene un par de décadas, sigue siendo útil el listado realizado por GIRALT (1996). 


\section{MAPA 1}

La red de señoríos de la región de frontera entre Aragón, Cataluña y Valencia, 1303-1307

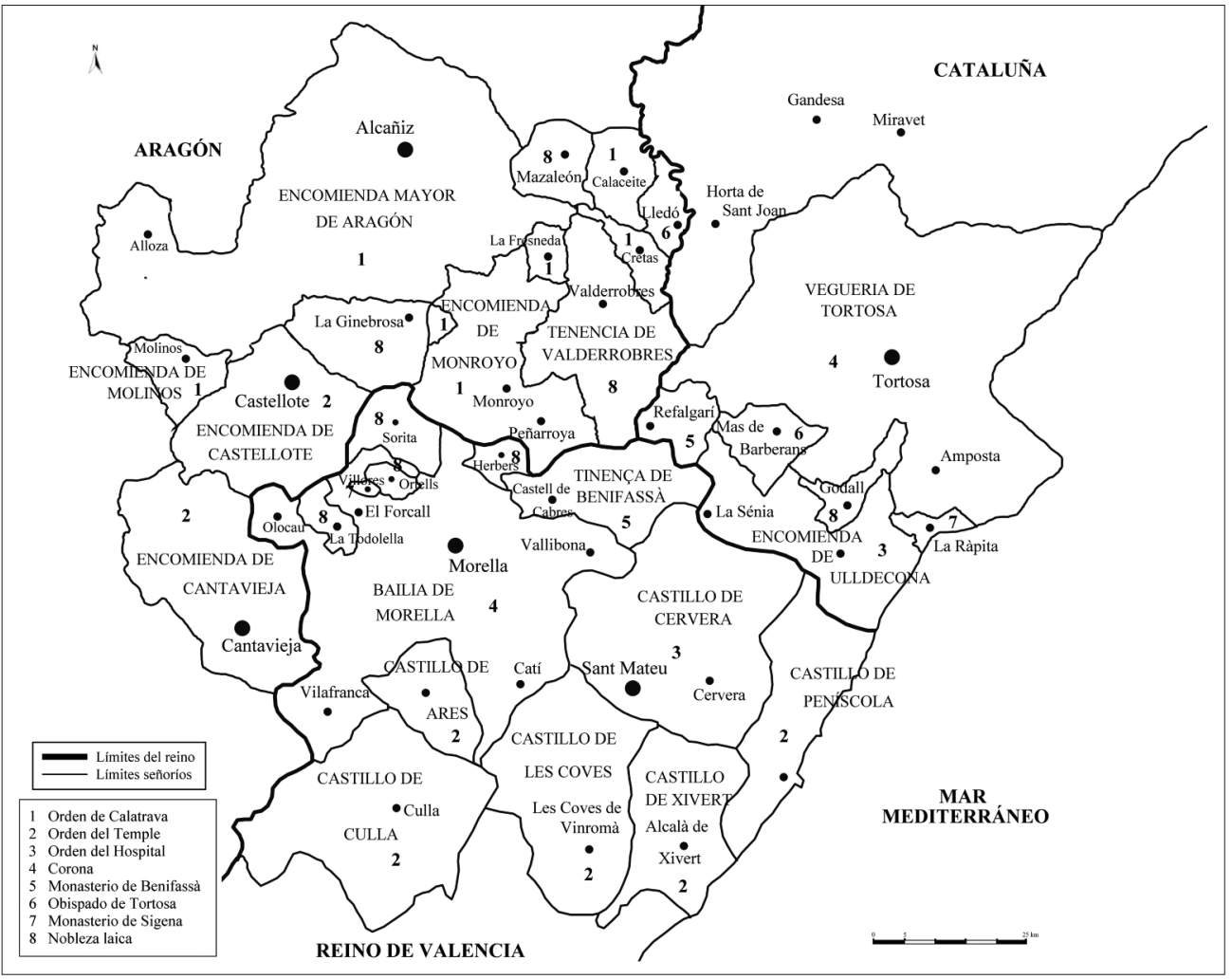

Fuente: elaboración propia.

Este es precisamente nuestro propósito: analizar la importancia de la ganadería y el sistema de gestión de las pasturas que se implanta en la región de frontera entre Cataluña, Aragón y Valencia durante los siglos bajomedievales. Todo este espacio comparte unas características geográficas y climáticas que contribuyen al desarrollo de una actividad que se convierte en el sustento económico principal de los habitantes de las diferentes villas y comunidades rurales. Evidentemente, la agricultura tiene un peso importante en las riberas del Ebro y en las zonas llanas de la región septentrional valenciana. Dicha actividad también está presente en las zonas interiores, pero los cultivos se sitúan en los reducidos espacios que ofrece un territorio montañoso y de suelos poco productivos (Laliena, 1987; Rabassa, 2005: 485-521; Royo, 2010b: 273-298). Por tanto, en la extensa franja de territorio que, a grandes rasgos, se encuentra entre Tortosa, Alcañiz, Cantavieja y Peníscola predomina un paisaje que favorece el desarrollo de la ganadería ovina. En todo este 
espacio, se combinan zonas de media montaña con otras llanas y, gracias a ello, se articula una trashumancia de media distancia que convive con otros movimientos de más largo alcance, que conectan esta región con los Pirineos (Le Roy Ladurie, 1975).

Ahora bien, la construcción de este amplio espacio ganadero no se realiza de manera inmediata, ni tampoco está exento de controversias. El proceso de conquista y colonización de la región, que tiene lugar entre mediados del siglo XII e inicios del siglo XIV, marca las pautas de la progresiva introducción de la ganadería ovina y la consiguiente transformación del paisaje. Asimismo, en la zona confluyen los intereses de reyes, nobles, obispos y órdenes militares, mientras que los habitantes de los concejos desarrollan reivindicaciones propias sobre el aprovechamiento de las pasturas. La convivencia entre los diferentes actores sociales no es sencilla y, lógicamente, existen divergencias entre los distintos espacios, debido al mayor o menor peso de la agricultura y la ganadería en las estrategias señoriales y campesinas en el ámbito local. En consecuencia, estalla una conflictividad que implica a todos los grupos sociales, atestigua las diferentes concepciones que tienen cada uno de ellos sobre la gestión de los recursos naturales y muestra los cambiantes equilibrios de fuerzas que existen entre los distintos colectivos durante los siglos bajomedievales. Gracias a este proceso de discusión constante, se articula un complejo sistema de funcionamiento de la ganadería que ayuda a definir la sociedad rural de esta vasta región de frontera ${ }^{3}$.

\section{EL NUEVO ORDEN AGRARIO}

La conquista del sur de Cataluña y Aragón se inicia a mediados del siglo XII, con las ocupaciones de Tortosa (1148), Lleida (1149) y Alcañiz (1150-1151). Mediante la incorporación de estas plazas, los cristianos sitúan la frontera con al-Ándalus en el río Ebro por la parte catalana, mientras que en la vertiente aragonesa los límites son más difusos por la inexistencia de un accidente natural que sirva de división. En efecto, la frontera se constituye como un espacio abierto, sometido a las idas y venidas de huestes que realizan incursiones periódicas en territorio enemigo en busca de botín y esclavos. Esta dinámica bélica y las propias concepciones de los conquistadores conllevan la introducción de cambios esenciales en la organización del territorio, que van a tener una importancia capital en el desarrollo de la ganadería con posterioridad.

3. A pesar de su importancia en la zona, la ganadería sólo se ha abordado, de manera parcial, en obras que perseguían otras motivaciones (GUINOT, 1986: 94-99, 302-318; LALIENA, 1987: 60-63, 245-248; 2016: 81-86, 165-172). Sí existen estudios específicos consagrados a su análisis (GuINOT, 1992-1993: 255-274; SÁNCHEZ ADELL, 1995: 445-487; RoYO, 2011: 123-142), pero se circunscriben a ciertos espacios de este territorio y no ofrecen una visión de conjunto, objetivo que se persigue aquí. 
Para empezar, muchos musulmanes habían huido ante los peligros de la guerra y, en el Bajo Aragón, son expulsados de manera mayoritaria después de la conquista ${ }^{4}$. En las riberas del Ebro, la población andalusí, mucho más numerosa, permanece en mayor grado, pero es redistribuida en poblaciones rurales y, sobre todo, en la nueva aljama de Tortosa (Virgili, 2001: 103-130). En efecto, tras la ocupación, el hábitat disperso de época andalusí se abandona y la población se concentra en un número menor de centros, que ofrecen buenas condiciones de defensa y son colonizados con cristianos dedicados fundamentalmente a las actividades militares. Debido a la proximidad de la frontera, la guerra marca el carácter de la sociedad que se implanta en la región y esto tiene su reflejo en unos fueros que otorgan una atención preferente a las cuestiones bélicas.

Ahora bien, reyes y señores saben que, si quieren que sus empresas militares tengan éxito, deben colonizar pronto estas posesiones y, para ello, conceden una serie de franquicias a aquellos que vayan a poblar estos lugares, que se concretan en la supresión de los vínculos de la servidumbre y la entrega de tierras sin la imposición de ningún censo o con el pago de un canon muy bajo. También otorgan el aprovechamiento libre de los recursos naturales del término que se concede a cada centro, de modo que los colonos pueden acceder a los pasturajes sin satisfacer ningún censo. El primer documento que recoge estos privilegios es la carta puebla de Tortosa, expedida por Ramón Berenguer IV en 1149. En este documento, el conde otorga a los habitantes de la ciudad montes et planos et boschos et ligneamina ad omnes vestros usus propios, para después añadir que les concede también prata et paschuas et venationes (Font, 1969: I, 121-124) ${ }^{5}$.

A partir de esta primera escritura, esta concesión se extiende al resto de las cartas puebla que se conceden en la Cataluña Nueva y el Bajo Aragón. Con ello, se pretende agilizar la formación de unas cabañas locales que puedan garantizar el abastecimiento de carne, pieles y lana de los nuevos centros. Además, a pesar de la vaguedad de estas expresiones, su aparición en los respectivos documentos tiene una importancia capital. Gracias a la aplicación sistemática de esta medida, las villas y las comunidades rurales adquieren unos derechos que después van a defender a ultranza, cuando se vean amenazados

4. Tan sólo se mantiene población musulmana en Alcañiz, Calanda y Foz Calanda (LALIENA, 2016: 75).

5. Fernández Mier, López Gómez y GonzÁlez Álvarez (2013: 192) sugieren que la aparición de conceptos diferenciados como pascuis y pratis en la documentación de la región cantábrica de los siglos IX-XI implica la existencia de una organización del territorio, que se plasma en las escrituras mediante esta distinción terminológica. Esto mismo se podría pensar en el caso que nos ocupa, porque dichas diferencias también aparecen en la documentación de la época y, por tanto, es posible que esta división entre pastos y prados proceda del periodo andalusí. Sin embargo, el desconocimiento del paisaje de secano durante esa época impide confirmar esta hipótesis. 
por sus señores o por las comunidades vecinas. En efecto, mediante las respectivas cartas de población, se organizan unos concejos municipales que aglutinan a todo el colectivo de vecinos y se convierten en el canal de reivindicación de las protestas campesinas, aunque todavía están fuertemente mediatizados por los señores y su autonomía es aún reducida (Laliena, 1987: 173-212).

Sin embargo, en estos momentos posteriores a la conquista, y más allá de estas expresiones genéricas, poco más se puede saber de la ganadería, porque las fuentes no aportan la información necesaria. Aun así, a tenor del contenido de las cartas puebla expedidas durante la segunda mitad del siglo XII y las primeras décadas del siglo XIII, es fácil pensar que en las riberas del Ebro la agricultura constituye la actividad predominante, porque, además de las excelentes condiciones geográficas, los colonos cuentan con las infraestructuras de irrigación heredadas de los musulmanes (Virgili, 2001: 197-224). En las zonas más meridionales de Cataluña y en el Bajo Aragón, donde predomina un terreno de secano, se tiende a poner en explotación las mejores tierras, dedicadas al cultivo de cereales y vid, de modo que se configuran unas comunidades rurales con un carácter agrícola. Los campesinos de estos centros deben aprovechar los pastos de los términos municipales para apacentar unos rebaños de unas pocas cabezas, que sirven para cubrir las necesidades familiares (Laliena, 2016: 85). Ahora bien, la documentación de principios del siglo XIII muestra que los señores tienen ya un cierto interés por la ganadería ${ }^{6}$.

En un intento de involucrar a las órdenes militares en la conquista de al-Ándalus, en 1208 y 1209 el rey Pedro el Católico confirma al Hospital y el Temple, respectivamente, los privilegios obtenidos por los frailes hasta ese momento ${ }^{7}$. Entre todas estas concesiones, se encuentra la exención de satisfacer cualquier impuesto relacionado con la ganadería en el realengo, de modo que los rebaños de los frailes y de sus vasallos pueden atravesar los términos de las villas reales y aprovechar los pastos sin pagar ningún canon ${ }^{8}$. Se estimula, así, la circulación de los ganados en unas rutas de media y larga distancia que comienzan a tomar forma en este momento y esto favorece la proliferación de unos rebaños que deben de ser cada vez más numerosos. Buena muestra de ello es que los señores se reservan espacios de uso exclusivo para sus ganados dentro de sus posesiones. En 1210, por ejemplo, en la carta puebla de Lledó, el obispo de Tortosa retiene para la

6. Esta dedicación ganadera de la clase señorial es también patente en la Cataluña Vieja en este mismo periodo (RIERA, 2007: 226).

7. En 1143, Ramón Berenguer IV ya había otorgado al Temple la exención del pago de peajes y lezdas de sus ganados, confirmada ahora (RIERA, 2007: 241).

8. Archivo Histórico Nacional (AHN), Órdenes militares, San Juan, carp. 617, núm. II; AHN, Códices y cartularios, cód. 594, pp. 8-11. 
sede episcopal dos dehesas que habían sido delimitadas anteriormente (Font, 1969: I, 324326). Este interés señorial por la ganadería aumenta en las décadas posteriores, cuando se ocupa la región septentrional valenciana.

\section{EL DESPEGUE DE LA GANADERÍA}

Tras casi un siglo de avance progresivo, los cristianos ocupan las comarcas de Els Ports y El Maestrat entre 1231 y 1233 . La rapidez de la conquista se explica por la baja densidad de población de la zona, porque muchos musulmanes habían huido ante la presión militar que ejercían los feudales desde el norte. Tras la ocupación, el rey Jaime I y los señores activan un proceso de reorganización del territorio que sigue las mismas pautas que en las zonas vecinas. La minoritaria población andalusí es concentrada en unas pocas aljamas de reducidas dimensiones, mientras que el resto del territorio es poblado con cristianos procedentes de Cataluña y Aragón ${ }^{9}$. Los señores ponen en marcha una colonización que, aunque se alarga hasta el siglo XIV, se concentra en las décadas centrales del siglo XIII y se concreta en la creación de medio centenar de comunidades rurales (Guinot, 1986: 31-86; Royo, 2017: 99-130; 2018: 77-89). Además, gracias a la estabilización de la frontera, se fundan también otros centros en las zonas próximas de Cataluña y Aragón, que completan una red de poblamiento integrada por cerca de un centenar y medio de comunidades rurales en todo este vasto territorio. $\mathrm{Al}$ frente de esta trama se sitúan cuatro centros urbanos: la ciudad de Tortosa, la plaza más importante de la región; las villas de Morella y Alcañiz, los centros más destacados del interior; y la villa de Sant Mateu, que se consolida en la zona llana de El Maestrat.

Ampliando la tradición anterior, las villas y comunidades rurales que se fundan a mediados del siglo XIII adquieren una personalidad jurídica propia y nacen con una estructura de gestión de los asuntos comunales que ya otorga un elevado grado de autonomía a los incipientes concejos. Asimismo, los señores conceden una serie de franquicias que siguen las mismas pautas establecidas anteriormente, entre las cuales está el libre uso de los recursos naturales de los términos municipales (Guinot, 2010a: 323-352). De hecho, se repiten casi las mismas cláusulas utilizadas antes y, en consecuencia, se establece una base común en el aprovechamiento de las pasturas. Aun así, es necesario hacer una distinción en la región septentrional valenciana.

9. En concreto, se crean tres aljamas en Cervera, Peníscola y Xivert, pero los musulmanes son expulsados en 1248 de los dos primeros lugares. En adelante, sólo persisten dos pequeñas poblaciones rurales habitadas por mudéjares, Xivert y El Molinell, en el castillo de Culla (Royo, 2017: 42-49, 105-106). 


\section{MAPA 2}

La red de poblamiento de la región de frontera entre Aragón, Cataluña y Valencia, 1303-1307

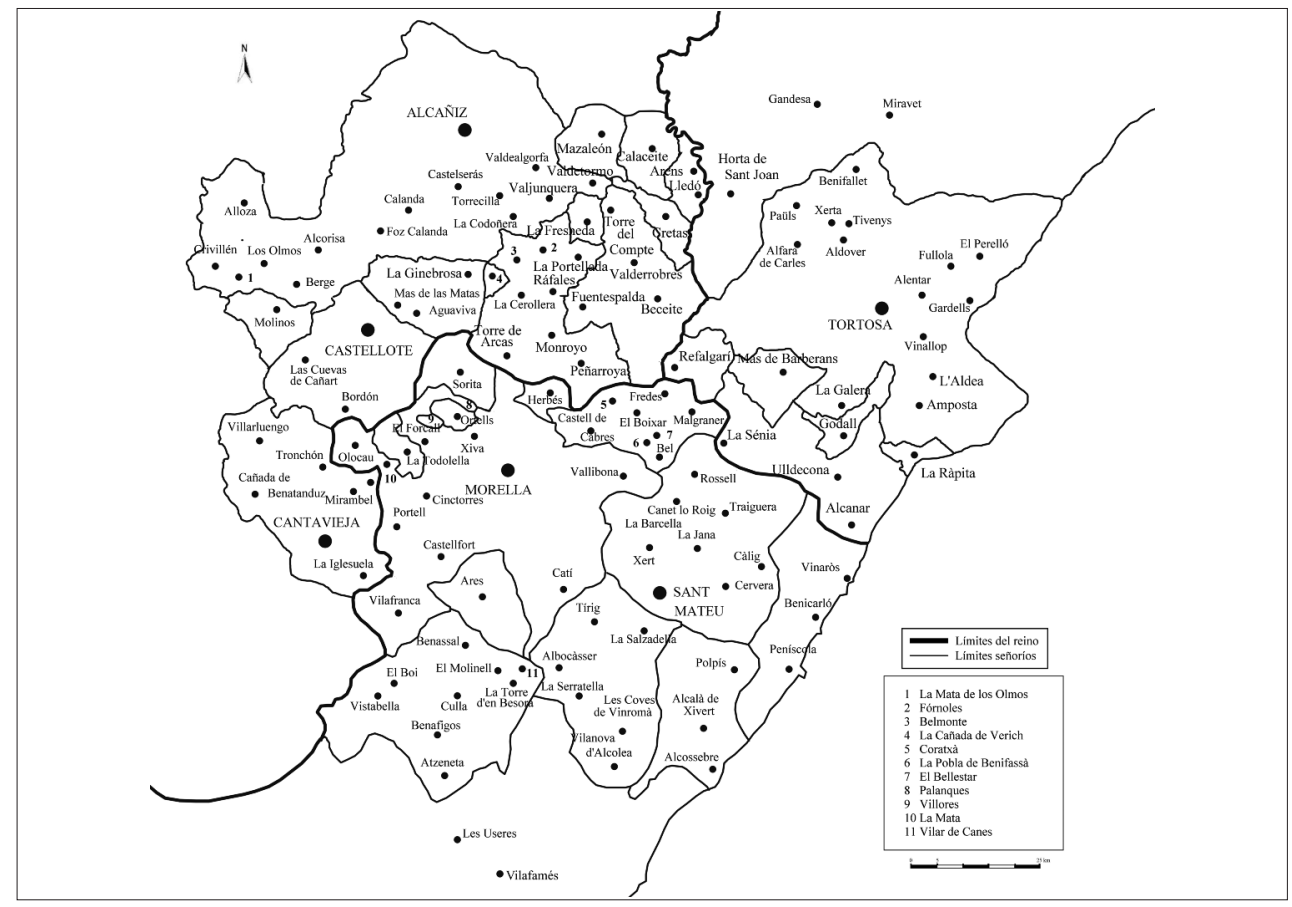

Fuente:elaboración propia.

En las zonas más llanas de El Maestrat, la monarquía, el Hospital y elTemple fundan comunidades rurales con un marcado carácter agrícola. En las respectivas cartas puebla, aunque se introducen cláusulas que gravan la ganadería, el verdadero interés de los señores se dirige hacia las actividades agrarias (Guinot, 1992-1993: 257-258). En cambio, en la villa y el término general de Morella -donde se asienta una caballería villana que dirige el centro urbano hasta finales del siglo XIII (Royo, 2018: 66-77)- y en el castillo de Culla, es decir, en las zonas más montañosas de la región, existe más atención hacia la ganadería, porque los espacios de cultivo son mucho más reducidos y hay mayores posibilidades de aprovechamiento ganadero y forestal. De hecho, la monarquía y los nobles que señorean ambos distritos desarrollan estrategias que muestran el interés creciente por la ganadería, pues reservan espacios para sus rebaños y también otorgan zonas vedadas a las incipientes comunidades rurales ${ }^{10}$.

10. En 1239, Blasco de Alagón se reserva un domenge en el término de Benassal y, en 1245, la orden de Calatrava hace lo propio cuando funda Vilanova d'Alcolea. Por su parte, Guillem d'Anglesola dis- 
Su actuación está en consonancia con el desarrollo que comienza a tener dicha actividad en Aragón. Ofrecen buena muestra de ello las cartas puebla de La Iglesuela del Cid (1241) y Mirambel (1243), en la encomienda templaria de Cantavieja. Ambas escrituras definen centros típicos de las regiones de frontera, donde la actividad militar tiene un papel esencial en la articulación del cuerpo social. En este contexto, el ganado mayor adquiere una importancia capital para las acciones bélicas y el transporte, de modo que el maestre del Temple regula con precisión los pagos que deben realizar sus vasallos por la tenencia de bestias mayores en concepto de diezmo ${ }^{11}$. Este mismo detalle se aplica a las tasas impuestas sobre el ganado menor, pues los vasallos deben satisfacer el diezmo y un censo por llevar a pasturar sus rebaños a territorio andalusi ${ }^{12}$. Igualmente, se especifican los cánones impuestos a aquellos que penetren en tierras musulmanas con ganado mayor, porque aún está presente la posibilidad de realizar incursiones en el espacio andalusí13.

En este momento, la frontera con al-Ándalus está lejos y resulta difícil pensar que los vecinos de estos dos modestos centros emprendan largos viajes con sus rebaños, cuando disponen de pastos más próximos y seguros. Sin embargo, este interés de la orden del Temple por gravar la ganadería muestra que la actividad se está consolidando en el entramado económico de la región y las cláusulas que se incluyen en los respectivos documentos constituyen la mejor evidencia de la existencia de una circulación de ganados que supera los límites de los señoríos. De hecho, tras la conquista del norte valenciano, la monarquía y los señores favorecen esta trashumancia, hasta crear un gran espacio de circulación de cabañas que une las montañas aragonesas con las costas valenciana y catalana (Sánchez Adell, 1995: 445-487) ${ }^{14}$.

pone en la carta puebla de Vistabella del Maestrat de 1251 que sus vecinos pueden facere bovalarium (GuINOT, 1991: 132-135, 182-183, 239-242).

11. Las cláusulas que aparecen en los dos documentos, tomadas casi literalmente de la carta puebla de Cantavieja de 1225, establecen que los vecinos que posean pullos, equinos aut vitulos quod posint unum dare pro dezima deben entregar un animal. Si vero non habeat tot pullos, equinos vel asinos aut vitulos quod posit unum dare pro dezima, det pro pullo, equino vel mullino XII denaros vel pro asino IIII et sex pro vitello.

12. Respecto del diezmo, se establece que, de ganato suo, los habitantes de ambos centros deben satisfacer duos corderos. En el caso de La Iglesuela, se dispone que todo aquel que in terra sarracenorum introducat centum capita de ganato minuto, debet dare $X$ solidos.

13. En La Iglesuela, se estipula que si bestia cum silla intraverit in terra sarracenorum et illuc vendita fuerit, debet dare unam mazmotinam, bos vero vel vaca vel asinus debet donare VII denarios. Estas condiciones se repiten en Mirambel, aunque con unos pagos menores. Las respectivas cartas puebla, en LEDESMA (1991: 206-209, 228-233).

14. Una trashumancia que todavía se mantiene en época moderna (CASTÁN, 2000: 143-154). 


\section{LA ARTICULACIÓN DE UN GRAN ESPACIO GANADERO}

A mediados del siglo XIII y debido a la lejanía de la frontera, se inicia una transformación del paradigma social del espacio de confluencia entre Cataluña, Aragón y Valencia. Los centros de la región empiezan a perder su carácter bélico y el cuerpo social que los integra comienza una lenta transición hacia otro modelo social y económico, que deja de girar en torno a la guerra. Este proceso de cambio se alarga hasta las primeras décadas del siglo XIV y, durante este periodo, la ganadería se convierte en la fuente principal de riqueza de la región (Royo, 2016: 123-132; 2018: 209-216). Había unos precedentes y unos condicionantes geográficos y climáticos que posicionaban la ganadería en una situación de partida idónea. Además, en este momento se consolida la industria textil de las ciudades del valle del Ebro, Barcelona, Valencia -todavía en menor medida- y las urbes italianas, que demanda grandes cantidades de lana. Existen, pues, ciertos factores que explican la reconversión hacia una dedicación ganadera que despierta un enorme interés en los diferentes sectores sociales ${ }^{15}$.Y este despegue se inicia mediante la supresión de las barreras que impiden la libre circulación de los rebaños y limitan los derechos de pastura en los territorios vecinos.

Esta tendencia ya había sido iniciada por la monarquía a principios del siglo XIII, cuando Pedro el Católico concedió franquicias de tránsito y pastura en el realengo al Hospital y el Temple ${ }^{16}$. Tras la conquista del norte valenciano, Jaime I sigue con esta política y, en 1233, ratifica los privilegios otorgados por sus antepasados a ambas instituciones, que ahora se extienden al reino de Valencia (Sánchez Almela, 1986: 206-209; Torre, 2009: 70-73). Igualmente, el rey impulsa la dedicación ganadera del monasterio cisterciense de Santa María de Benifassà, fundado a instancias del propio monarca en 1233 (Royo, 2018: 45-57). De hecho, las tierras que componen su señorío son ciertamente pobres para la agricultura e, incluso, para la ganadería, de modo que los monjes buscan obtener pasturajes en los espacios vecinos más llanos.

En 1237, el monarca permite al monasterio que sus ganados puedan pasturar libremente en las tierras de realengo ${ }^{17}$. En 1244, el castellán de Amposta, de la orden del Hospital, otorga al cenobio libertad de pasturas en el castillo de Cervera, mientras que el comendador de Alcañiz, de la orden de Calatrava, realiza una concesión similar en los

15. En Castilla, se detecta este mismo fenómeno de transformación hacia una economía agropecuaria tras el alejamiento de la frontera (GARCÍA DE CORTÁzAR, 1993: 51-68).

16. Las referencias, en la nota 7 .

17. Arxiu de la Catedral de Tortosa (ACT), Llibre de Benifassà. 
castillos de Les Coves y Polpís ${ }^{18}$. En 1252, Jaime I entrega al monasterio un territorio yermo de cinco yugadas de extensión (unas 15 hectáreas) entre Vinaròs y Ulldecona, en la zona llana que separa Valencia y Cataluña, para edificare domos et corralia seu statica ad vestrum bestiare recolligendum, y en 1253 le dona la alquería de Irta, al sur de Peníscola $^{19}$. Con estas concesiones, el monasterio de Benifassà y sus vasallos pueden desarrollar en unas mejores condiciones una actividad ganadera que es casi la única fuente de riqueza que les permiten tener las tierras que habitan, pues disponen de pastos de verano en sus lugares de origen y de lugares para guardar sus rebaños durante los duros inviernos de la Tinença de Benifassà.

Por su parte, los señores también llegan a acuerdos similares. En 1242, los maestres del Hospital y el Temple rubrican una sentencia arbitral que establece la libertad de pasturas de sus ganados en sus posesiones (Pagarolas, 1999: II, 72-74). Con el establecimiento de este pacto, los frailes y sus vasallos obtienen una amplia libertad de movimientos, porque en estos momentos ambas instituciones controlan gran parte de los señoríos en esta región de frontera ${ }^{20}$. Se configura, así, un amplio espacio de circulación de rebaños que intensifica la dedicación ganadera de las órdenes militares y, por extensión, de los habitantes de sus señoríos.

Se pueden traer a colación muchos ejemplos que siguen esta misma dirección, pues durante el siglo XIII los señores amplían las zonas de pastura mediante pactos similares. Ahora bien, la proliferación de las cabañas también provoca que los señores intenten sacar un provecho económico con la introducción de impuestos que gravan la estancia y el paso de los rebaños por los distritos señoriales. En 1269, la orden de Calatrava comienza a exigir el pago del herbaje a todos los ganados que permanezcan más de dos días dentro del señorío, tanto a los rebaños trashumantes como a los de sus vasallos de las encomiendas de Alcañiz y Monroyo. Esta acción rompe con la tradición implantada mediante las cartas puebla y provoca las protestas de sus vasallos. Finalmente, sus quejas tienen efecto: en 1277, Calatrava concede a la villa de Alcañiz el privilegio de hacer uso de los pastos de toda la encomienda mayor de Aragón, una franquicia que se extiende a Calaceite en 1278 (Laliena, 2016: 86).

18. AHN, Códices y cartularios, 1.126-B, ff. 154-154v y ff. 160v-161.

19. Archivo de la Corona de Aragón (ACA), Pergamins de Jaume I, núms. 1.299 y 1.354.

20. El Hospital posee la castellanía de Amposta y la encomienda de Ulldecona, en Cataluña; los castillos de Cervera y Olocau, en el reino de Valencia; y la encomienda de Aliaga, en Aragón. Por su parte, los templarios señorean las encomiendas de Miravet, Riba-roja, Horta y Ascó, en Cataluña; el castillo valenciano de Xivert y las encomiendas aragonesas de Cantavieja y Castellote. 
Este ejemplo es suficientemente ilustrativo de las contradicciones generadas en el proceso de articulación de la sociedad rural. La monarquía y los señores han seguido una política de crear grandes zonas de circulación de rebaños que estimula la dedicación ganadera de los habitantes de los concejos, que aprovechan las franquicias negociadas por sus señores para participar en las rutas trashumantes que se organizan en la región. Ahora bien, al mismo tiempo, intentan introducir pagos por el aprovechamiento de los pastos, cuando los concejos habían obtenido libertad de pasturas en los respectivos términos municipales a través de las cartas de población y, por tanto, se oponen a estas novedades impositivas que rompen con el tradicional uso de los recursos naturales. Emerge, entonces, una confrontación entre señores y concejos que además estalla en un contexto tremendamente complejo en la región, que deviene uno de los escenarios del enfrentamiento entre la monarquía y la nobleza aragonesa durante la unión.

Aunque las acciones bélicas se concentran en ciertos momentos (1283, 1286 y 1290), la inestabilidad es constante durante las dos últimas décadas del siglo XIII, porque las huestes de los nobles aragoneses con posesiones en la zona protagonizan diferentes saqueos de las poblaciones vecinas. Además, cuentan con el apoyo de sus vasallos, que participan en sus mesnadas, secuestran el ganado que transita por los términos señoriales y municipales, y exigen el pago de impuestos por el paso y la estancia de los rebaños en dichos distritos, a pesar de las franquicias que alegan sus propietarios (Guinot, 1986: 141-166). Todo este clima de tensión provoca la intervención del rey Jaime II, que transforma profundamente la red señorial de la zona.

En 1293, el rey pacta con el noble Artal de Alagón la entrega de sus señoríos valencianos de Peníscola, Les Coves y Ares, que el monarca concede al año siguiente al Temple a cambio de la ciudad de Tortosa. Los templarios unen estas nuevas posesiones al castillo valenciano de Xivert y a las encomiendas aragonesas de Cantavieja y Castellote, que ya señoreaban antes, y completan sus dominios en 1303 con la adquisición del castillo de Culla (Royo, 2017: 60-62). Gracias a estas permutas y transacciones, el Temple reúne un gran estado territorial en esta región de frontera y, en su interior, se articula una trashumancia entre las zonas llanas y las de montaña que va a beneficiar tanto a los frailes como a sus vasallos ${ }^{21}$.

Un documento redactado entre 1294 y 1303 muestra la intensa circulación que existe entre los señoríos templarios. En un año de ese periodo -el registro no está fechado-, los

21. De hecho, desde 1288, el Temple exime del pago de herbaje y carnatge (impuesto que recae sobre los animales destinados a la alimentación) en el castillo de Xivert a los rebaños de los vecinos de la encomienda de Cantavieja. ACA, Cancelleria Reial, reg. 74, f. 66v. 
habitantes del castillo de Culla, señorío todavía del noble Guillem d'Anglesola, secuestran a los vecinos de Alcalá de Xivert, Les Coves de Vinromà, La Salzadella, Albocàsser y Ares un total de 2.370 cabezas de ganado menor y 37 cabezas de ganado mayor cuando se dirigían a las encomiendas de Cantavieja y Castellote ${ }^{22}$. Como es lógico, estas cifras sólo son una pequeña muestra de las enormes cabañas que transitan entre las posesiones templarias. Por otra parte, las transformaciones políticas introducidas por la monarquía consiguen apaciguar la zona de manera progresiva, pero el clima de tensión todavía persiste unos años y, evidentemente, los cambios en la titularidad de los señoríos no erradican los problemas concernientes a la ganadería, que genera intensas contradicciones entre los diferentes grupos sociales.

\section{LA EMERGENCIA DE LOS CONCEJOS}

En el tránsito de los siglos XIII y XIV, la sociedad implantada tras la conquista da muestras de una gran solidez. En estos momentos, las comunidades rurales tienen una demografía que oscila entre el centenar y los dos centenares y medio de familias, mientras que las villas rondan el millar de hogares (Royo, 2017: 138-148). El crecimiento demográfico ha sido notable desde la conquista y, además, la ganadería ya ha adquirido una importancia capital en el entramado económico de la región. Los centros están habitados por una amplia capa de campesinos que combinan la tenencia de modestos rebaños con diversificados patrimonios agrarios. Del mismo modo, en las villas y las comunidades rurales aparece un reducido sector de grandes propietarios de ganado, que disponen de extensas explotaciones agrarias donde apacentar sus reses y aprovechan las vías abiertas por la monarquía y los señores para practicar una trashumancia de media distancia. Más aún, también se lanzan por cuenta propia a obtener pasturajes en espacios cercanos.

En 1316, cuatro vecinos de Vilafranca del Cid arriendan tres dehesas en el término de Culla, unos vedados que cubren un tercio del distrito municipal y cuya explotación consiguen durante un año por 1.000 sueldos. Estas mismas condiciones se establecen en 1333, cuando otros diez habitantes de Vilafranca arriendan una dehesa en Les Useres ${ }^{23}$. Existe, pues, una iniciativa particular protagonizada por grandes ganaderos locales, capaces de movilizar capitales importantes para obtener pastos complementarios para sus rebaños y organizar pequeños movimientos trastermitantes, que también les permiten ampliar sus ya numerosas cabañas. Además, esta capa de grandes propietarios de ganado suele estar al frente de los concejos y aprovechan la cobertura institucional de los municipios para

22. Un ganado valorado en 14.068 sueldos, 2 dineros. ACA, Cartes reials, Jaume II, caja 132, núm. 38 .

23. Arxiu Històric Notarial de Morella (AHNM), núm. 2, 20/09/1316 y núm. 4, 03/10/1333. 
protagonizar acciones colectivas destinadas a ensanchar las zonas de pasto comunales en detrimento de sus vecinos ${ }^{24}$.

A finales del siglo XIII, los centros rurales y urbanos se desligan progresivamente del control ejercido por los señores y adquieren una mayor autonomía en la gestión de los asuntos comunitarios, un aspecto que redunda en el fortalecimiento de los gobiernos a nivel local (Laliena, 1987: 185-206). A su frente, se distingue ya una oligarquía que asume la dirección de los concejos (Guinot, 2010b: 409-430). Estas directrices son especialmente visibles en los centros urbanos, que refuerzan su posición dominante en la trama de poblamiento. En el caso de la ganadería, los dirigentes urbanos ponen en marcha un agresivo proceso de extensión de sus derechos de pasto, que combinan con la férrea defensa de sus intereses en el ámbito local. Cuentan, además, con el respaldo de la monarquía cuando pertenecen al patrimonio real, pues su fortaleza contribuye a consolidar la posición de la Corona en el tablero geoestratégico de la región. En este sentido, el mejor ejemplo lo constituye la villa de Morella.

El centro urbano y su amplio término general se incorporan al patrimonio real en 1239 y, desde ese momento, la Corona sigue una política de fortalecimiento de la villa. En 1242, la reina Violante otorga a Morella y sus aldeas las dehesas de Vallivana y Salvassòria, de uso exclusivo de sus vecinos (Royo, 2018: 93). En 1271, Jaime I constituye el tribunal del Lligallo de Morella, una institución a través de la cual se gestiona la actividad ganadera en el término general ${ }^{25}$. En 1273, exime a los vecinos de la villa y sus aldeas del pago del herbaje en dicho distrito. Asimismo, estipula que, en los dominios señoriales, sólo deberán pagar por este impuesto lo mismo que satisfacen los hombres de Teruel en las tierras del rey en el reino de Valencia. Por último, dispone que, en caso de que se creen nuevos vedados en el resto de los señoríos, los vecinos de Morella y sus aldeas conservarán los derechos que tenían antes de la creación de estos $\operatorname{cotos}^{26}$. Gracias a estas medidas, los habitantes de la comarca de Els Ports consiguen unas facultades que impulsan su dedicación ganadera, pero también provocan el estallido de una problemática que comienza a ser general en la región.

De hecho, en el tránsito de los siglos XIII al XIV, los dirigentes de Morella tienen frentes abiertos con todos los señores y concejos vecinos por la fijación de las fronteras de los respectivos distritos (Royo, 2018: 65). Las autoridades urbanas llevan a cabo una polí-

24. Esto mismo sucede en Castilla (Monsalvo, 2001: 89-122).

25. Aureum opus regalium privilegiorum civitatis et regniValentie. Extravagantes, núm. I, f. 234v. Se analizará su funcionamiento en el apartado siguiente.

26. ACA, Cancelleria Reial, reg. 21, f. 142v. 
tica que consiste en anexionar partidas limítrofes a sus términos generales, dejar de pagar el herbaje allá donde deben hacerlo y perturbar a los rebaños que transitan por la comarca, aunque sus propietarios tengan las correspondientes exenciones. De este modo, exigen el herbaje a los vasallos del monasterio de Benifassà, al mismo tiempo que pretenden aprovechar libremente los recursos naturales de su señorío alegando que se encuentra dentro de los términos generales de la villa (Royo, 2018: 189). Asimismo, Morella asume la defensa de Olocau del Rey en el enfrentamiento que el lugar mantenía con Monroyo y sus aldeas, hasta que el conflicto se cierra en 1317 con un convenio que establece una comunidad de pastos entre ambas villas y sus aldeas, de modo que los dos términos generales se constituyen como un gran espacio pastoril destinado a la producción de lana (Laliena, 2016: 86). Finalmente, retoman una vieja disputa iniciada en la época de la conquista por una zona limítrofe con el castillo de Cervera ${ }^{27}$.

El conflicto se intensifica a partir de 1316, cuando el castellán de Amposta crea la dehesa de El Turmell, de uso exclusivo de los vecinos del castillo de Cervera (Díaz Manteca, 1987: 410-411). Esta sierra es un punto estratégico en las rutas que unen las montañas aragonesas y la costa valenciana, y la orden del Hospital cierra este espacio para consolidar los derechos de sus vasallos. Esta acción suscita la reacción de Morella, que se aferra al privilegio de 1273 para justificar el derecho de uso de este coto creado después de la recepción de dicha franquicia. Finalmente, el litigio se resuelve en 1323 mediante un arbitraje, según el cual se respeta la dehesa de El Turmell, aunque el límite entre los términos de Morella y Cervera se sitúa en el pico de la sierra y, así, ambas partes disponen de un lado de la montaña (Sánchez Almela, 1986: 371-375). De hecho, gracias al laudo, la villa articula un espacio de pastura continuo en el extremo de su término general, pues las dehesas de Gibalcolla, Salvassòria, Vallivana y Vallibona, que ya poseía, ahora quedan unidas a través de la vertiente occidental de El Turmell (Royo, 2017: 73-79).

$\mathrm{Al}$ otro lado del río de La Sénia, la ciudad de Tortosa pone en práctica una política similar. Las transformaciones del último cuarto del siglo XIII complican enormemente la situación por el cruce de jurisdicciones y derechos que existe, y el centro urbano aprovecha este complejo entramado para consolidar su predominio en la región meridional catalana. En 1280, la villa de Amposta pasa a manos de la Corona (Royo, 2017: 57), que en 1294 también incorpora Tortosa ${ }^{28}$. Estas dos transacciones modifican el equilibrio de fuerzas establecido por hospitalarios y templarios anteriormente y, en adelante, los dirigentes de Tortosa llevan a cabo una estrategia de presión que toma tres direcciones diferentes.

27. En 1235, Blasco de Alagón, señor de Morella, y el castellán de Amposta ya firman una concordia para determinar la posesión de esta partida. ACA, Cancelleria Reial, reg. 614, f. 13v.

28. ACA, Cancelleria Reial, reg. 614, f. 27. 
Para empezar, perturban a los frailes del Temple en el uso de las dehesas que conservan en el término general de Tortosa y les exigen los preceptivos impuestos por transitar por el distrito. Aunque la orden conservaba todos los derechos de que había disfrutado anteriormente, los dirigentes urbanos invaden los espacios del Temple con sus rebaños e, incluso, organizan milicias para presionar a los frailes ${ }^{29}$. Por otra parte, las acciones también se dirigen contra la orden del Hospital y sus vasallos de Ulldecona, aunque este enfrentamiento se cruza con el conflicto que inician las autoridades de Tortosa con el monasterio de Benifassà y la villa de Morella.

El motivo de esta disputa radica en el privilegio que concede Jaime II a la ciudad en 1293, pues sus vecinos quedan exentos de satisfacer cualquier impuesto referente a la ganadería en los dominios reales en el reino de Valencia (Massip, 1995: I, 223). Esta concesión abre el camino de las cabañas de Tortosa al término general de Morella y, de hecho, el mismo año del privilegio, la presión ejercida sobre el monasterio de Benifassà surte efecto. Ese año, el abad Ramon Bernat y los dirigentes de Tortosa rubrican una concordia según la cual la ciudad catalana obtiene libertad de pasturas en cuatro partidas del señorío del monasterio que son limítrofes con el término general de Tortosa (Fabregat, 1988: 114-115, 116). Este acuerdo es completado por otros dos de 1297 y 1298, que fijan las condiciones de estancia de los ganados en dichas partidas y establecen los límites entre los distritos de Tortosa y Morella, que se encuentran en este punto (Fabregat, 1988: 116; Massip, 1995: I, 372, 421).

Estos pactos allanan el camino a los habitantes de La Sénia y Ulldecona, que pretenden obtener prerrogativas similares. Las protestas comienzan, como mínimo, en 1313 y, siete años después, la presión ejercida da sus frutos, porque una sentencia arbitral de Jaime II autoriza a los vecinos de ambos lugares a aprovechar libremente las tierras yermas de las mismas partidas que ya habían conseguido los habitantes de Tortosa. Eso sí, en compensación a esta pérdida, el monarca decreta la creación de una dehesa que será de uso exclusivo de los vasallos del monasterio ${ }^{30}$. De hecho, esta es una de las soluciones más comunes para garantizar la preservación de pastos frente a las pretensiones externas.

29. En 1296, un notario de Tortosa reúne una hueste de 23 hombres a caballo que ataca la dehesa templaria de Burjassénia y ordena a los pastores que se encuentran en la zona que invadan dicho vedado, dels quals bestiars intraren [...] pus de mil CCC cabeces, entre cabrú e de lana (PAGAROLAS, 1999: II, 237-239).

30. Los lugares de La Sénia y Ulldecona deberán satisfacer 7.000 sueldos por el aprovechamiento de estos espacios, delimitados en 1321 con mayor precisión (BAYERRI, 1952: 41-43, 52-55, 88-89). 


\section{CREACIÓNY GESTIÓN DE LOS ESPACIOS COMUNALES}

La intensificación del tránsito de los rebaños por las franquicias negociadas entre los señores y la presión que ejercen las villas y las comunidades rurales sobre los lugares vecinos generan una intensa conflictividad. Frente a esta problemática, los concejos adoptan las soluciones arbitradas anteriormente por sus señores y destinan importantes cantidades de dinero para cerrar ciertos espacios de los términos municipales y señoriales, que serán de uso y gestión comunal y que sólo podrán disfrutar los vecinos del lugar o del señorío, pues los rebaños foráneos tienen vetado el acceso, aunque sus propietarios dispongan de libertad de pasturas en los respectivos distritos. En concreto, se constituyen dos tipos de vedados: los boalares y las dehesas. Los primeros, generalmente, son zonas de pasto cercanas a los pueblos, que sirven para apacentar los animales de labranza y transporte. Los segundos suelen estar más alejados de los centros, en espacios con pasturas más abundantes, que se emplean para el ganado menor (Ferrer, 1990: 526). De este modo, se crean zonas acotadas dentro de los términos municipales y señoriales con el objetivo de asegurar el mantenimiento del ganado de labor y de la amplia cabaña local de ganado menor, en un proceso que es ciertamente prolongado en el tiempo ${ }^{31}$.

Los primeros testimonios son de principios del siglo XIII y la iniciativa corresponde a los señores, aunque los campesinos también participan. Al ejemplo ya mencionado de Lledó de 1210 se une el de Calaceite, pues mediante la carta puebla de 1207 sus señores ceden su dehesa a los vecinos del lugar (Ledesma, 1991: 176-177) ${ }^{32}$. Ahora bien, a pesar de estos tempranos casos, el proceso de establecimiento de vedados en favor de los concejos arranca a mediados del siglo XIII en el sur de Cataluña y Aragón, el término general de Morella y el castillo de Culla, las zonas donde se desarrolla antes la actividad ganadera, y se extiende hasta mediados de la centuria siguiente en la región septentrional valenciana. De hecho, en El Maestrat tiene lugar con un cierto retraso, pues el mayor auge se produce en los años anteriores y posteriores a la fundación de la orden de Santa María de Montesa (1317-1319) ${ }^{33}$. Ahora bien, cuando se inicia, el proceso de establecimiento de vedados es mucho más rápido e intenso en esta comarca que en el resto del territorio, porque existe la ingente necesidad de proteger los derechos locales frente a las pretensiones foráneas.

31. La situación de los comunales en Castilla, en Monsalvo (2007: 141-178).

32. Este proceso de acotación de las zonas yermas también comienza a finales del siglo XII en el norte de Cataluña (RIERA, 2007: 224).

33. Más detalles de la fundación de la orden y su señorío, que reúne las posesiones del Hospital y el Temple en el reino de Valencia, en García-Guijarro (1989: 69-83). 
La villa de Sant Mateu ofrece un buen ejemplo de esta celeridad, aunque la política que sigue este centro refleja la dinámica existente en el resto del territorio anteriormente. En 1313, las autoridades urbanas obtienen del castellán de Amposta la concesión de la dehesa de Comenyer, por 15.000 sueldos (Sánchez Almela, 1986: 240-241). En 1316, el castellán otorga a todos los centros del castillo de Cervera la dehesa de El Turmell, que cubre todo el término municipal de La Barcella y gran parte del distrito de Xert (Díaz Manteca, 1987: 410-411). En 1326, frente a la insuficiencia de pastos que aluden los dirigentes de la villa, el maestre de Montesa, Arnau de Soler, le cede la dehesa de Camer, que hasta ese momento había explotado la orden, por 1.000 sueldos (Díaz Manteca, 1987: 413-415). Sin embargo, esta concesión resulta problemática, porque una parte del vedado se encuentra dentro del término de Cervera del Maestrat y sus dirigentes protestan en 1329 por las donaciones realizadas en favor de la villa (Sánchez Almela, 1986: 208-210).

En este litigio, el maestre Pere de Tous mantiene los derechos concedidos a Sant Mateu, pero su aparición muestra los problemas derivados del proceso de acotación de los términos municipales y, sobre todo, de las actuaciones de las autoridades locales en la gestión de los boalares y las dehesas. Porque, en efecto, cuando los señores cierran los respectivos espacios, también transfieren a sus vasallos las facultades para administrarlos. De hecho, les otorgan la potestad de emitir una normativa específica para gestionar las condiciones de acceso a los cotos - para determinar el tipo y el número de animales que pueden entrar y las épocas en que pueden hacerlo-, y nombrar a guardias que velan por el cumplimiento de estas leyes locales. Asimismo, les conceden el derecho de castigar a los vecinos y forasteros que infrinjan las normas que regulan el paso y la estancia por dichos espacios y en los cultivos, una capacidad punitiva que se traduce en degollar ciertas cabezas del ganado que penetra en los cotos o los campos sin licencia o en el pago de ciertas cantidades de dinero según el número de animales que cometen la infracción.

Gracias a estas concesiones, las villas y las comunidades rurales obtienen una gran autonomía en la gestión de los vedados, que se refleja en los libros de ordenanzas locales, donde se recoge la normativa emitida por los dirigentes locales sobre la actividad ganadera y la administración de los cotos. De manera progresiva, las autoridades locales imponen un complejo sistema de control de los diferentes espacios, mediante una normativa que se adapta a las transformaciones impuestas por las coyunturas, por ejemplo, en épocas de escasez de pastos o de agua ${ }^{34}$. En última instancia, los dirigentes de los concejos conocen la gran capacidad de gestión que pueden asumir sobre los recur-

34. En 1324, por ejemplo, los jurados de Herbers prohiben la estancia de ganado local y forastero en la dehesa del lugar entre marzo y noviembre debido a la falta de pasturas (GUINOT, 2006: 168). 
sos naturales y, a causa de la transcendencia de la ganadería para las economías domésticas, se lanzan a obtener la administración de todas las pasturas de los términos respectivos.

Aunque, en principio, los señores asumen su gestión por los importantes ingresos que proporcionan, esta tendencia se transforma en el siglo XIV. En un intento de optimizar el funcionamiento de la hacienda señorial, los señores tienden a desprenderse de los derechos relacionados con las pasturas, que ceden a sus vasallos a cambio de una renta anual. Así, se despreocupan de la enorme problemática que genera la ganadería y obtienen una cantidad de dinero fija cada año que, si bien no reporta los ingresos que puede llegar a producir un estricto control de la actividad, sí proporciona una cantidad que garantiza estabilidad a la economía señorial. En este sentido, el ejemplo más ilustrativo lo constituye la encomienda de Culla.

En 1345, las comunidades rurales del distrito obtienen del maestre de Montesa, Pere de Tous, la gestión del herbaje en toda la encomienda, a cambio del pago anual de 1.600 sueldos. Los motivos que aduce Tous para efectuar la concesión son claros: el control de la ganadería genera a la orden molts e diverses dans, mientras que las rentas s'arrendaven antigament a les deventades més, a les devengades menys. En consecuencia, Tous les otorga l'erbatge e herbatges dels bestiars grosses e menuts [...] de tots los térmens de la dita tinença, y el derecho sobre tres dehesas en el término de Benassal, que la orden tenía arrendadas por el pago anual de dos cahíces de trigo. Eso sí, el maestre dispone que sus vasallos no pueden alienar este derecho y que sus ganados y los rebaños del comendador de Culla podrán aprovechar libremente las pasturas de la encomienda ${ }^{35}$.

Gracias a esta concesión, los habitantes del distrito consiguen libertad de pasturas por toda la encomienda y, además, se articula la Setena dels Herbatges de la Tinença de Culla, un organismo que está integrado por los síndicos de las respectivas comunidades y cuya función es gestionar el aprovechamiento de los pastos. Cada año se celebra una reunión a la que acuden los representantes de los centros para conocer el estado de las pasturas en la encomienda, repartir el importe de la renta que deben satisfacer a la orden y adoptar las medidas necesarias, como delimitar las zonas a las que se puede acceder, decidir si se permite o se deniega el acceso a rebaños foráneos y establecer los pagos que deben satisfacer en caso de dejarles entrar. Se estructura, así, un sistema de funcionamiento colectivo que genera una reglamentación muy precisa, recogida en los Llibres dels capitols dels herbatges (Barreda, 1986: 446-562). Esta normativa, discutida y aprobada en

35. En cambio, los otros frailes de Montesa tendrán que pagar dos sueldos por cada centenar de cabezas de ganado menor y cuatro dineros por cada animal mayor (DíAz MANTECA, 1987: 299-307). 
las reuniones anuales, es fruto del consenso y se actualiza con el paso del tiempo, adaptándose a las necesidades de cada momento.

Ahora bien, este entramado colectivo no anula la iniciativa particular de cada comunidad, pues los centros mantienen las prerrogativas pertinentes dentro de sus términos municipales. Las autoridades locales pueden recaudar las rentas proporcionadas por el tránsito y la estancia de ganados forasteros según las disposiciones de la asamblea general, conservan la capacidad de promulgar leyes para regular la actividad en las tierras que no son declaradas de uso común y disponen de la facultad de aplicar las penas que correspondan, según la normativa local y la común. De hecho, el maestre transfiere a sus vasallos el derecho de juzgar todas las causas derivadas del uso de las pasturas en los términos municipales, quedando el maestre o el comendador como tribunal de apelación.

Una función distinta cumple el tribunal del Lligallo. Esta institución tiene su origen en el sur de Aragón y, durante los siglos XIII y XIV, es exportada a tierras catalanas y valencianas ${ }^{36}$. En Cataluña, está documentado el tribunal del Lligallo de Tortosa (Puig, 1953: 125). En 1271, el rey Jaime I crea dicha institución en Morella, que tiene jurisdicción sobre todo el término general de la villa ${ }^{37}$. En 1358, el maestre de Montesa, Pere de Tous, instituye el Lligallo de La Jana, que engloba dicho lugar y los de Canet lo Roig, Rossell, Càlig y La Barcella, en la encomienda de Cervera (Díaz Manteca, 1987: 263-265). De nuevo, las diferencias cronológicas en los distintos espacios de la región muestran la progresiva implantación de la ganadería, que triunfa más tarde en El Maestrat. Sin embargo, a pesar de esta divergencia temporal, el objetivo y el funcionamiento de estos tribunales son prácticamente los mismos.

Esta institución está destinada a controlar los ganados que transitan por los términos respectivos, mantener en buen estado las infraestructuras necesarias para la ganadería y, especialmente, controlar los animales que se pierden en dichos distritos. De hecho, se celebran dos reuniones anuales para devolver el ganado perdido a sus propietarios y, si no aparece, venderlo para cubrir los posibles daños ocasionados y los gastos causados en su custodia (Gual, 1970: 69-84). Para gestionar estas funciones, anualmente las autoridades municipales eligen a un vecino que ocupa el cargo de justícia, magistrado con autoridad para secuestrar cabezas de ganado e imponer penas pecuniarias a aquellos que cometan cualquier infracción. Cuenta, además, con la colaboración de guardias que velan por el cumplimiento de las leyes locales y custodian el ganado perdido hasta ser devuelto

36. Se tiene constancia del tribunal del Lligallo de Teruel al menos desde 1258. ACA, Cancelleria Reial, reg. 10, f. 109v.

37. La referencia, en la nota 25. 
a su dueño o vendido en subasta pública si no aparece. Finalmente, en el tribunal de Morella, el oficial que lo dirige gestiona también el cobro del herbaje en el término general (Milián, 1927: 175-185) ${ }^{38}$.

Así pues, a lo largo del siglo XIV, los concejos toman las riendas de la actividad ganadera. Para ello, desembolsan importantes cantidades de dinero para acotar espacios de uso exclusivo dentro de sus términos municipales y, así, garantizar las pasturas para el ganado local. También desarrollan una normativa que regula la estancia y el paso de los rebaños por los respectivos distritos y asumen el cobro de los impuestos derivados de la ganadería después de adquirir el derecho de sus señores. En última instancia, se articulan diferentes instituciones, de ámbito local o comarcal, que pretenden administrar la actividad ganadera. Se desarrolla, pues, un estricto sistema de control de la ganadería, pero esta actuación no erradica unos conflictos que se acentúan a finales del siglo XIV.

\section{UNA ETAPA CONTRADICTORIA}

En el último cuarto del siglo XIV, todo este vasto territorio atraviesa un contexto tremendamente complejo. Desde la época de la conquista, la región conoce un periodo de crecimiento generalizado, pero las crisis frumentarias de los años treinta del siglo XIV, la peste de 1348 y la guerra con Castilla (1356-1375) introducen distorsiones en el comportamiento demográfico, con sus particularidades regionales. Las tierras aragonesas y catalanas experimentan un cierto retroceso a partir del primer tercio de dicha centuria (Laliena, 2016: 152-163), mientras que en la zona valenciana la población sigue aumentado y se alcanza el máximo demográfico hacia los años setenta del siglo XIV (Guinot, 1988: 229-249). En este momento, las comunidades rurales tienen una población que oscila entre el centenar y los tres centenares de hogares, mientras que las villas alcanzan el millar o millar y medio de familias. Ahora bien, la presión fiscal y la reproducción sistemática de pestes y carestías en la segunda mitad del siglo XIV comportan importantes cambios, pues estimulan la migración hacia los lugares más dinámicos y se producen fuertes descensos de la población en ciertos periodos, factores que determinan una progresiva tendencia de regresión demográfica. Sin embargo, estas dificultades tie-

\footnotetext{
38. Ahora bien, no todos los lligallos tienen las mismas funciones. Aparte de los mencionados, se tiene constancia de sendos tribunales en Xert, Cervera, Culla, Olocau y Torre del Compte (RABASSA, 1992: 97), seguramente creados en el siglo XIV. Eso sí, su ámbito es estrictamente local y los oficiales que los dirigen no tienen jurisdicción ni tampoco capacidad punitiva. Más bien, se trata de cargos menores en la administración local que sólo se ocupan de gestionar los animales perdidos en los términos municipales.
} 
nen lugar al mismo tiempo que aumentan las oportunidades de enriquecimiento gracias al comercio de lana.

A finales del siglo XIV, los mercaderes italianos se instalan en la región para obtener directamente la materia prima necesaria que abastecerá la industria textil de sus ciudades de origen (Rabassa, 2008: 177-204). La introducción de este espacio en los circuitos del comercio internacional intensifica la actividad ganadera, aunque también agudiza la diferenciación en el interior de los centros. La base del tejido social sigue compuesta por una amplia capa de pequeños ganaderos que sufren con intensidad las consecuencias de la crisis y, de hecho, necesitan cada vez más los rebaños que les ceden a medias los grandes propietarios para garantizar su subsistencia. Estos últimos, por su parte, amplían sus tierras y sus cabañas gracias a los negocios con los mercaderes extranjeros, controlan el comercio de lana y dominan la industria textil que se desarrolla en los centros rurales (Royo, 2010a: 25-56). Se acentúa, por tanto, una distinción social y económica que exacerba las tensiones, pues los grandes ganaderos locales aprovechan el dominio que ejercen sobre los concejos para promulgar leyes favorables a sus intereses.

Sin ir más lejos, los integrantes de la oligarquía local autorizan la constitución de cotos particulares dentro de los términos municipales, aparte de los vedados comunales. Por ejemplo, en las ordenanzas del lugar de Castellfort de 1374, se dispone que cascú en sa heretat [...] pugue fer devesa o bovalar o cerrada per a obs de ses bèsties de arada o de son bestiar, siempre que reúna una explotación compacta que supere las cinco cahizadas de extensión (alrededor de tres hectáreas) y cuente con la aprobación de los jurados (Guinot, 2006: 444). Evidentemente, sólo los campesinos más ricos se benefician de esta medida, porque son los que poseen las explotaciones y las cabañas más amplias. Ahora bien, sus decisiones no siempre son bien aceptadas por sus vecinos.

Aunque el ejemplo provenga de una zona situada más al sur, ilustra perfectamente los conflictos que se generan en el interior de las comunidades rurales. En 1380, el maestre de Montesa, Berenguer Marc, cede al lugar de Vilafamés (Mapa 2) el control de los pastos del término municipal a cambio de una renta anual de 1.500 sueldos $^{39}$. Sin embargo, el desembolso del censo pronto deviene un problema. En 1388, un grupo de campesinos medianos y modestos exigen al maestre que el pago no lo asuma la comunidad (era repartido entre todos los vecinos en proporción a su riqueza), sino que corra a cargo únicamente de los propietarios de ganado. Por su parte, los ganaderos defienden el mantenimiento de la concesión inicial y piden que se conserve el modelo de reparto anterior. Finalmente, Marc toma una decisión de consenso y establece que los vecinos que posean

39. AHN, OO. MM., Montesa, libro 542-C, ff. 79-84. 
ganado paguen el $75 \%$ del censo y la comunidad se haga cargo del resto, dividido en proporción a la riqueza de cada contribuyente ${ }^{40}$.

Tensiones como esta entre ganaderos y agricultores e, incluso, entre los mismos propietarios de ganado son habituales debido a la aparición de pretensiones contrapuestas. La misma situación se reproduce entre los diferentes concejos. Las transformaciones demográficas de finales del siglo XIV alteran los equilibrios sobre los que se cimentaron los pactos anteriores y, en consecuencia, es necesario renovar dichos acuerdos. En 1408, por ejemplo, los dirigentes de Morella y Tortosa pactan que los vecinos de Morella y sus aldeas podrán abrevar libremente sus ganados en el distrito de la ciudad catalana y sólo tendrán que pagar una vez por hacerlo en el río de La Sénia, mientras que las cabañas de los hombres de Tortosa podrán pacer y transitar libremente en los términos de Morella (Puig, 1953: 125). La ciudad de Tortosa disfrutaba de esta franquicia desde 1293, pero sistemáticamente había sido vulnerada y el privilegio real original debe ser ratificado por un pacto particular entre los dos centros urbanos. Ambos necesitan sancionar un acuerdo que facilite el desarrollo de una actividad tremendamente conflictiva, pero que es el principal sustento económico de la región.

Evidentemente, la situación se transforma en el siglo XV por los cambios demográficos (las tierras aragonesas y catalanas inician una lenta recuperación, mientras que se agudiza el descenso de la población en la zona valenciana) y la desaparición de la demanda extranjera de lana. Sin embargo, cuando llegan estas dificultades, ya se ha alcanzado un nivel de especialización productiva que se mantiene durante toda la centuria. Según el censo de 1510, se contabilizan 86.847 cabezas de ganado en Els Ports, repartidas entre las 1.470 casas que se computan en los 23 lugares de la comarca. En El Maestrat, hay 132.096 reses, distribuidas entre los 2.798 hogares contabilizados en los 28 centros de la comarca. Además, aunque existen diferencias patrimoniales, prácticamente en todos los concejos las medias superan las sesenta cabezas por casa y en algunos centros se computan medias de más de doscientas reses por hogar ${ }^{41}$. Estas cifras atestiguan que, a finales de la Edad Media, se mantiene la estructura integrada por una amplia capa de pequeños propietarios de ganado y un reducido grupo de grandes ganaderos locales, que aprovechan el sistema de gestión de los recursos naturales implantado en los siglos precedentes. Sobre esta articulación se cimienta la reconstrucción posterior a la crisis.

40. AHN, OO. MM., Montesa, ff. 126v-127. La conflictividad asociada a los usos del espacio rural en Castilla, en Monsalvo (2010).

41. Los datos han sido extraídos de VAlldeCABRes (2002: 192, 226-238, 256-259, 260-285, 286 $301,304-308,312-324,325-326,465-466,475-501)$. 


\section{CONCLUSIÓN}

Entre los siglos XII y XIV, se constituye un enorme espacio ganadero en la región de frontera entre Cataluña, Aragón y Valencia. La ganadería se convierte en la principal actividad económica y esto tiene una enorme incidencia en la organización social y territorial. A medida que la frontera con los musulmanes se aleja, la ganadería cobra fuerza y, a mediados del siglo XIII, tras la conquista del norte valenciano, los diferentes actores sociales se inclinan definitivamente por la dedicación ganadera. Como es lógico, este proceso presenta diferencias en los distintos espacios de la región, pues la casuística local es muy diversificada y existen factores geográficos, climáticos, sociales y económicos que introducen divergencias. Ahora bien, a pesar de estas lógicas diferencias, los distintos grupos sociales articulan respuestas similares a problemáticas comunes y, gracias a ello, se estructura un ámbito de circulación de personas, rebaños y capitales en un territorio que sigue una misma dinámica.

En las décadas centrales del siglo XIII, la monarquía y los señores promueven la ganadería mediante privilegios que impulsan el tránsito de los rebaños y el libre aprovechamiento de las pasturas. Se articula, así, un intenso trasiego de las cabañas en una trashumancia de media distancia que conecta los pastos de verano de las montañas aragonesas con los de invierno de las costas catalana y valenciana. Gracias a estas franquicias, los habitantes de los diferentes centros pronto dirigen su atención a la ganadería y se empieza a multiplicar el número de cabezas de ganado que recorren las cañadas y ocupan los términos municipales. Surgen, pues, intereses contrapuestos que derivan en el estallido de una conflictividad que se hace patente a finales del siglo XIII.

En estos momentos, las villas y las comunidades rurales ya han alcanzado la madurez social e institucional suficiente para asumir la defensa de sus intereses. Tras los pasos iniciales de los señores, los concejos toman las riendas de los pleitos por la fijación de los límites de los términos municipales y señoriales y ofrecen ingentes cantidades de dinero a sus señores para apropiarse de una parte de estos distritos, con el fin de cerrar unos espacios que serán de uso exclusivo de sus vecinos. Entre mediados de los siglos XIII y XIV, tiene lugar la fase más importante de establecimiento de dehesas y boalares, cuya administración pertenece a los gobiernos locales. De este modo, existe un primer control de las pasturas a nivel local que pronto sobrepasa los límites municipales.

A medida que se consolidan los órganos municipales y se afianza la dedicación ganadera de la población, los dirigentes locales obtienen de sus señores la gestión de todos los asuntos relacionados con la ganadería en los señoríos y las bailías reales. En consecuencia, se articulan diferentes sistemas comunales de gestión de los espacios ganaderos que 
obligan a los concejos a desarrollar unos organismos de administración colectivos, destinados a administrar el paso y la estancia de los rebaños por los términos respectivos. Gozan, pues, de una enorme autonomía para manejar la actividad ganadera y esto explica las soluciones que se adoptan durante la segunda mitad del siglo XIV frente a los recurrentes problemas que causa la ganadería.

Si un centenar de años antes habían sido los reyes y los señores los protagonistas de la articulación de un espacio de circulación del ganado, ahora corresponde a los concejos modificar los antiguos pactos. A partir de mediados del siglo XIV, las transformaciones demográficas generan nuevos equilibrios y la demanda extranjera de lana intensifica la dedicación ganadera de la región. En este contexto, los concejos necesitan entablar nuevas negociaciones para intentar amoldar la antigua articulación a las nuevas circunstancias y a sus propios intereses. Como es lógico, sus actuaciones no acaban con las dificultades creadas por la actividad ganadera y tampoco resuelven la compleja convivencia entre agricultura y ganadería, pero su papel director muestra la transformación que se ha producido en la gestión de los recursos naturales.

Durante los siglos XIV y XV, las villas y las comunidades rurales asumen la dirección en el proceso de discusión que se genera alrededor de la ganadería. Sustentan, además, su actuación en unos órganos de gobierno municipales plenamente consolidados, que sirven para canalizar las reivindicaciones colectivas, y cuentan también con otras instituciones comunales plenamente asentadas a finales de la Edad Media. De hecho, estos organismos colectivos mantienen su pervivencia en los siglos posteriores, porque se basan en una acción consensuada, que explica su perdurabilidad en el tiempo. La crisis demográfica que azota este territorio desde la segunda mitad del siglo XIV y la sensible reducción de la demanda extranjera a partir de mediados del siglo xv no desarticulan el entramado construido durante las centurias anteriores. Contrariamente, el posterior proceso de reconstrucción se lleva a cabo sobre la especialización ganadera y la estructura institucional cimentadas en esta época, aunque con las lógicas modificaciones que exige una sociedad rural sometida a un proceso de cambio constante.

\section{AGRADECIMIENTOS}

Me gustaría agradecer a José-Miguel Lana Berasain, Damián Copena Rodríguez, Iñaki Martín Viso, David Pérez Neira y, muy especialmente, a Margarita Fernández Mier los comentarios realizados en el transcurso de la sesión plenaria «Recursos naturales, acción colectiva y culturas igualitarias: Propiedad, organización y gestión comunales desde la Edad Media a la transición agroecológica", que tuvo lugar en el marco del XVI Con- 
greso de Historia Agraria de la SEHA, celebrado en Santiago de Compostela en 2018. Aprovecho también para agradecer a los revisores de Historia Agraria las consideraciones realizadas en la evaluación del trabajo, pues sus comentarios han ayudado a replantear el enfoque inicial del presente estudio y, sin duda, a mejorar el resultado final. Evidentemente, todos los posibles errores que contenga el texto sólo son atribuibles a su autor.

\section{REFERENCIAS}

AlanyÀ, L \& Cabanes, M. D. (Eds.) (1515). Aureum opus regalium privilegiorum civitatis et regniValentie. Valencia: Anúbar. (Edición facsímil, 1972. Original publicado en Valencia).

BARREDA, P. E. (1986). Llibre dels capítols d'herbatges de la Tinença de Culla (13451805). Boletín de la Sociedad Castellonense de Cultura, (LXII), 446-562.

BAYERRI, E. (1952). Llibre dels privilegis de la vila de Ulldecona: Cartulario de la militar y soberana Orden de San fuan de ferusalén (ahora de Malta) en su Comendoría de Ulldecona, desde mediados del siglo XII hasta finales del XVI. Tortosa: Imprenta Blanc.

Bourin, M. (2007). Aspectos y gestión de los espacios incultos en la Edad Media: Nuevos enfoques en la Francia meridional. En A. RodríGuez LóPEz (Ed.), El lugar del campesino: En torno a la obra de Reyna Pastor (pp. 179-192). Valencia: Consejo Superior de Investigaciones.

Brumont, F. (Ed.) (2008). Prés et pâtures en Europe Occidentale. Toulouse: Presses universitaires du Mirail.

CASTÁN, J. L. (2000). Aproximació a l'estudi de les rutes transhumants entre Aragó iValència durant l'Edat Moderna. Estudis d'història agrària, (14), 143-154.

Díaz Manteca, E. (Ed.) (1987). El «Libro de Poblaciones y Privilegios» de la Orden de Santa María de Montesa (1234-1429). Castelló de la Plana: Diputació de Castelló.

FABREgat, I. (1988). Annals del Monestir de Santa Maria de Benifassà (1195-1586). Tesis de licenciatura inédita. Valencia: Universitat de València.

Fernández Mier, M., López Gómez, P. \& González Álvarez, D. (2013). Prácticas ganaderas en la cordillera cantábrica: Aproximación multidisciplinar al estudio de las áreas de pasto en la Edad Media. Debates de Arqueología Medieval, (3), 167-219.

FERrER, M.T. (1990). Boscos i deveses a la Corona catalano-aragonesa (segles XIV-XV). Anuario de Estudios Medievales, (20), 485-539.

FonT, J. M. (1969). Cartas de población y franquicia de Cataluña. 2 vols. Madrid: [s. n.]. García de Cortázar, J. A. (1993). De una sociedad de frontera (el valle del Duero en el siglo $\mathrm{x}$ ) a una frontera entre sociedades (el valle del Tajo en el siglo XII). En Las sociedades de frontera en la España medieval: Aragón en la Edad Media: II Seminario de Historia Medieval, sesiones de trabajo (pp. 51-68). Zaragoza: Universidad de Zaragoza. 
García-Guijarro, L. (1989). Los orígenes de la Orden de Montesa. En Las órdenes militares en el Mediterráneo occidental (s. XII-XVIII) (pp. 69-83). Madrid: Casa de Velázquez/Instituto de Estudios Manchegos.

Gerbet, M. C. (2003). La ganadería medieval en la Península Ibérica. Barcelona: Crítica.

GIRALT, E. (Dir.) (1996). Contribució a una bibliografia per a la història de la ramaderia i la veterinària als Països Catalans. Barcelona: Centre d'Estudis Historics Internacionals.

Giralt, E. (Dir.) (2004). Història agrària dels Països Catalans. II: Edat Mitjana. Barcelona: Fundació Catalana per a la Recerca.

GuAL, M. (1970). La institució ramadera del «ligallo»: Unes ordenances desconegudes del segle XIv. Estudis d'Història Medieval, (II), 69-84.

GuINot, E. (1986). Feudalismo en expansión en el norte valenciano: Antecedentes y desarrollo del señorio de la Orden de Montesa, siglos XIII-XIV. Castelló de la Plana: Diputación de Castelló.

Guinot, E. (1988). Demografia medieval del nord del País Valencià. En C. PÉREZ APARICIO (Ed.), Estudis sobre la població del País Valencià (pp. 229-249).Valencia: Alfons el Magnànim/Centre Valencià d'Estudis i d'Investigació.

GuINot, E. (Ed.) (1991). Cartes de poblament medievals valencianes. Valencia: Generalitat Valenciana.

Guinot, E. (1992-1993). La ramaderia al Maestrat medieval: Entre l'expansió i la crisi. Estudis Castellonencs, (5), 255-274.

Guinot, E. (Ed.) (2006). Establiments municipals del Maestrat, els Ports de Morella i Llucena (segles XIV-XV). Valencia: Universitat de València.

Guinot, E. (2010a). La génesis de las comunidades campesinas cristianas en Valencia y Andalucía tras la conquista del siglo XIII. En J. I. DE LA IGLESIA DuARTE (Coord.), Monasterios, espacio y sociedad en la España cristiana medieval (pp. 323-352). Logroño: Instituto de Estudios Riojanos.

GuINOT, E. (2010b). Oligarquías y clientelismo en las comunidades rurales del sur de la Corona de Aragón. Hispania. Revista española de historia, (70), 409-430.

Jover, G. (1994). La crisi tardomedieval i el desenvolupament d'una ramaderia senyorial: Mallorca, segles XIv-XvI. Butlletí de la Societat Catalana d'Estudis Històrics, (5), 81-99.

LAFFont, P.Y. (Ed.) (2006). Transhumance et estivage en Occident: Des origines aux enjeux actuels. Toulouse: Presses universitaires du Mirail.

LALIENA, C. (1987). Sistema social, estructura agraria y organización del poder en el Bajo Aragón en la Edad Media (siglos XII-XV). Teruel: Instituto de Estudios Turolenses.

Laliena, C. (Coord.) (2016). Matarranya, gentes y paisajes en la Edad Media. Valderrobres: Gobierno de Aragón. 
Le Roy Ladurie, E. (1975). Montaillou, village occitan de 1294 à 1324. Paris: Gallimard. Ledesma, M. L. (Ed.) (1991). Cartas de población del reino de Aragón en los siglos medievales. Zaragoza: Institución Fernando el Catolico.

Martín GutiÉrRez, E. (2015). Paisajes, ganadería y medio ambiente en las comarcas gaditanas: Siglos XIII al XVI. Cádiz: Universidad de Cádiz.

Massir, J. (1995). Inventari de l'Arxiu Històric de Tortosa. Tarragona: Diputació de Tarragona.

Milián, M. (1927). Notas para la historia del Lligalló de Morella. Boletín de la Sociedad Castellonense de Cultura, (VIII), 175-185.

Monsalvo, J. M. (2001). Usurpaciones de comunales: Conflicto social y disputa legal en Ávila y su Tierra durante la Baja Edad Media. Historia agraria: Revista de agricultura e historia rural, (24), 89-122.

Monsalvo, J. M. (2007). Comunales de aldea, comunales de ciudad-y-tierra: Algunos aspectos de los aprovechamientos comunitarios en los concejos medievales de Ciudad Rodrigo, Salamanca y Ávila. En A. RodRíGuez López (Ed.), El lugar del campesino: En torno a la obra de Reyna Pastor (pp. 141-178). Valencia: Consejo Superior de Investigaciones.

Monsalvo, J. M. (2010). Comunalismo concejil abulense: Paisajes agrarios, conflictos y percepciones del espacio rural en la tierra de Ávila y otros concejos medievales. Ávila: Diputación de Ávila.

Pagarolas, L. (1999). Els templers de les Terres de l'Ebre (Tortosa): De faume I a l'abolició de l'Orde (1213-1312). Tarragona: Diputació de Tarragona.

PAscua, E. (2007). Las otras comunidades: Pastores y ganaderos en la Castilla medieval. En A. RodRíGuez López (Ed.), El lugar del campesino: En torno a la obra de Reyna Pastor (pp. 209-238). Valencia: Consejo Superior de Investigaciones Científicas.

Pascua, E. (2012). Señores del paisaje: Ganadería y recursos naturales en Aragón, siglos XIII-XVII. Valencia: Universidad de Valencia.

Puig, J. (1953). Historia breve y documentada de la Real Villa de Catí. Castelló de la Plana: Diputación de Castellón.

RabASSA, C. (1992). Puntualitzacions sobre la institució ramadera del Lligallo: El Lligallo de Culla. Millars. Espai i Història, (15), 81-98.

Rabassa, C. (2005). Estructura agrària de Culla, 1431-1504. Boletín de la Sociedad Castellonense de Cultura, 81 (2), 485-521.

RABASSA, C. (2008). Comerç mediterrani i mercaderies locals: Una perspectiva des de les comarques septentrionals valencianes (segle Xv). En J. J. FERRER \& P. BARCELó (Dirs.), Europa: Historia, imagen y mito (pp. 177-204). Castelló de la Plana: Universitat Jaume I.

RIERA, A. (2004). La ramaderia pagesa als comtats catalans (segles IX-XI). Estudis d'història agrària, (17), 751-764. 
RIERA, A. (2007). El valor dels erms: La gestió de les pastures a Catalunya (segles XI-XIII). En F. SABATÉ (Coord.), Natura i desenvolupament: El medi ambient a l'Edat Mitjana (pp. 221-250). Lleida: Pagès.

Royo, V. (2010a). Elits rurals i xarxes mercantils al nord del País Valencià baixmedieval: El comerç i la manufactura de la llana a Vilafranca (1393-1412). Recerques: Història, economia i cultura, (60), 25-56.

Royo, V. (2010b). Un paisatge agrari de muntanya en el segle XV. Horts, terres i masos a Culla en 1431. Territori i Societat: El paisatge històric. Història, arqueologia, documentació, (v), 273-298.

Royo,V. (2011). L'influence de l'élevage dans l'organisation du paysage du village de $\mathrm{Cu}-$ lla (Xve-XvII siècles). Domitia. Revue du Centre de Recherches Historiques sur les Sociétés Méditerranéennes, (12), 123-142.

Royo, V. (2016). Vilafranca (1239-1412): Conflictes, mediacions de pau $i$ arbitratges en una comunitat rural valenciana. Castelló de la Plana: Universitat Jaume I.

Royo,V. (2017). Els orígens del Maestrat històric: Identitat, convivència $i$ conflictes en una societat rural de frontera (s. XIII-XV). Benicarló: Onada Edicions.

Royo, V. (2018). Les arrels històriques de la comarca dels Ports: Societat, poder $i$ identitat en una terra de frontera durant la Baixa Edat Mitjana. Benicarló: Onada Edicions.

SÁNCHEZ AdELl, J. (1995). Aportaciones a la historia de la ganadería medieval de las comarcas del norte castellonense (Ports de Morella, Benifaçà y Maestrazgo de Montesa). Boletín de la Sociedad Castellonense de Cultura, (71), 445-487.

Sánchez Almela, E. (Ed.) (1986). El Llibre de Privilegis de la Villa de Sant Mateu (11571512). Castelló de la Plana: Caja de Ahorros y Monte de Piedad de Castellón.

Slicher van Bath, B. H. (1978). Historia Agraria de Europa Occidental, 500-1850. Barcelona: Península.

TORRE, S. DE LA (2009). El cartulario de la encomienda templaria de Castellote (Teruel), 1184-1283. Zaragoza: Universidad de Zaragoza.

VALLDECABRES, R. (Ed.) (2002). El cens de 1510: Relació dels focs valencians ordenada per les Corts de Montsó. Valencia: Universitat de València.

VIrgili, A. (2001). Ad detrimentum Yspanie: La conquesta de Turtusa i la formació de la societat feudal (1148-1200). Valencia: Universitat de València. 